\title{
Cultural Factors Contributing to Maternal Mortality Rate in Rural Villages of Limpopo Province, South Africa
}

This article was published in the following Dove Press journal: International Journal of Women's Health

\section{Portia Maphale Marabele Maria Sonto Maputle (D) Dorah Ursula Ramathuba Lizzy Netshikweta}

Department of Advanced Nursing Science, University of Venda, Thohoyandou, South Africa
Correspondence: Maria Sonto Maputle Department of Advanced Nursing Science, University of Venda, Private Bag X5050,

Thohoyandou 0950, South Africa

Tel +27 I5 9628I25

Fax +27 86667I 337

Email sonto.maputle@univen.ac.za
Introduction: The understanding of the link between cultural affairs and maternal health is critical to save the lives of women. The South African maternal mortality rate (MMR) target for 2015 was 38/100,000 live births. In 2017, South Africa had 1,222 maternal deaths. The purpose was to determine the perceived cultural factors contributing to MMR in rural villages in Mopani District.

Methods: This qualitative research and non-probability purposive sampling was used to select participants who met the inclusion criteria. Thirty women, age 40 years and above childbearing age, who had given birth in their lifetime, were sampled. Data were collected through in-depth individual interviews at the women's homes. Probing to elicit more information was conducted focusing on hemorrhage, hypertension and risk of contracting human immunodeficiency virus (HIV). Data were analyzed through open coding methods. Trustworthiness was ensured by Guba and Lincoln's criteria, credibility, dependability, confirmability, and transferability.

Results: From the study three themes emerged from the data as cultural factors relating to heavy, red post-delivery bleeding perceived as cleaning-out of the womb. With hypertension, gaining weight rapidly before the 20th week of gestation not reported as a pregnancy was still culturally concealed. Contracting HIV, women were exposed to unsafe sex practices due to cultural expectations of having children as a sign of femininity.

Discussion: The formulation of culture congruent interventions to promote good and acceptable cultural practices that cannot harm the physical and mental status of women was recommended to reduce unplanned deaths among them.

Keywords: hemorrhage, human immunodeficiency virus, hypertension, maternal mortality rate, perceived cultural factors

\section{Introduction}

Globally, more than half a million women die in childbirth, due to deaths occurring in developing countries, and about half in sub-Saharan Africa. ${ }^{1}$ In 2017 South Africa had 1,222 maternal deaths, Limpopo province had 181 deaths and for 5 deaths, causes were unknown. Out of these deaths, were from 28 deaths. ${ }^{2}$ The Department of Health ${ }^{3}$ reported that more than 4,300 mothers die every year due to complications of pregnancy and childbirth. Women die from preventable causes related to pregnancy and childbirth, ${ }^{4}$ hemorrhage being the leading cause of maternal death in the regions. Further prolonged or obstructed labour, sepsis, disorders of pregnancy, especially eclampsia, and complications of unsafe abortions 
were documented to cause maternal deaths. In South Africa, the commonest causes of maternal deaths were HIV/AIDS, hypertension, and hemorrhage. ${ }^{5}$ The high rate of maternal mortality was found amongst women who reside in rural areas and poorer communities. ${ }^{4}$ According to Zureick-Brown and Chou, ${ }^{6}$ maternal mortality is regarded as a key indicator of population health, social and economic development. In Sub-Saharan Africa, the sociocultural factors have been highlighted as significant contributors to maternal mortality. The highlighted socioeconomic factors were illiteracy, poverty, ignorance, poor nutrition and poor use of available maternal services), whereas cultural, religious factors, poor transport and telecommunication and biological factors which included age and parity differential were cited as significant contributors. ${ }^{7}$ On the part of the health sector, the deficit in obstetric emergency care provision in rural areas was found to have played an important role in maternal mortality. ${ }^{7}$ Hence Okolocha et $\mathrm{al}^{8}$ concluded that full understanding of maternal morbidity and mortality, could be important when considering factors like cultural determinants. These determinants may include paucity of facilities to deal with obstetric emergencies, harmful traditional medical beliefs and practices and strict male control and restriction of women's access to medical care. The studies on sociocultural norms influences which are used in maternity services focusing on general communities. $^{9-11}$ It is therefore important to conduct the study in the rural community because their belief systems could be incorporated into the interventions that are recommended to improve maternal care.

Cole and Packer, ${ }^{12}$ viewed culture as a universal human experience with a clear picture of psychological and protective factors of pregnancy in cultural contexts. It is documented that previous research focused on biomedical causes and treatments for maternal mortality and largely neglected realities in countries where maternal mortality remained high, due to culture and traditional health practices which dictate what should happen during childbirth. ${ }^{13}$ The indigenous beliefs and practices that shape the cultural traits are passed from one generation to the next. Shaikh and Hatcher ${ }^{14}$ were of the notion that cultural aspects of pregnancy are often neglected, whereas, these practices are deeply rooted and embedded in the societies. Cultural practices become part of the people's lifestyle and it becomes difficult to change their beliefs and practices. It can be concluded that belief systems could play a major role in health-care-seeking behavior of the family members. It is documented that three conditions that contribute to the majority of preventable maternal deaths in South Africa were identified for 2008-2010 as non-pregnancy related infections, obstetric hemorrhage, and complications of hypertension in pregnancy. ${ }^{15}$ The South African committee summarized its recommendations into five key points which can be referred to as the 5H's namely HIV/AIDS, hemorrhage, hypertension, health worker training and health system strengthening. In this study the focus was on the 3H's, hypertension, hemorrhage, and HIV/AIDS, and cultural factors that contribute to maternal mortality rate in Ba-Phalaborwa municipality, Mopani District.

Hypertensive disorders during pregnancy is known as pregnancy-induced hypertension (PIH) which is a multiorgan disease which predominantly affects the circulatory system, renal system, central nervous system, coagulation, and liver. ${ }^{16}$ The placental immunological or chemical defect causes a prostaglandin imbalance, which affects the endothelium (lining) of blood vessels resulting in spasm of blood vessels, platelet aggregation, and leakage of plasma from capillaries. ${ }^{17} \mathrm{PIH}$ can lead to severe maternal and fetal complications like placental abruption when the placenta pull aways from the wall of the uterus causing maternal and fetal distress, temporary kidney failure, liver problems, pulmonary edema, and intracerebral hemorrhage. ${ }^{18} \mathrm{PIH}$ constitutes $14 \%$ of maternal mortality in developing countries because in its early stage a woman may totally be unaware of its presence. ${ }^{17}$ Screening for hypertension is simple and inexpensive. Findings by James et $\mathrm{al}^{19}$ on pregnant women's attitudes and beliefs about PIH indicated that $80 \%$ of women visit the hospital only when noticing swollen legs and $60 \%$ associated swollen legs with superstition. Complications of hypertension in pregnancy remained the most common direct cause of maternal deaths.

Hemorrhage during childbirth can occur during pregnancy, labour, and postnatally. Bleeding in pregnancy is always worrying, but it is also surprisingly common. ${ }^{20}$ There can be several possible reasons. Women presenting with a history of missed menstrual period, positive pregnancy test, an episode of vaginal bleeding, usually showed high level of anxiety. In the study conducted by Maputle et $\mathrm{al}^{21}$ found that cultural stereotype influences decisions, for example, not to tell other people about what's happening with the pregnancy or the gestational age because the pregnancy will be aborted. The cultural attitudes to health care in general, and uterine bleeding in particular, influenced the provision of care to affected women. For example, it has been culturally noted that a regular, heavy, red menstrual bleeding is perceived as providing a "healthy 
clean-out of the womb," and this could contribute to substantially delaying presentation for professional care. ${ }^{22}$ Culture also determined gender norms that deny women the ability to make their own decisions, seek care without their husbands' or other family members to make decisions on their own contributes to maternal mortality. Cultural stigma in the communities, for example husbands in the community who insist on their women doing difficult household chores when they are pregnant, can play a serious impact on maternal mortality due to hemorrhage from placenta abruption in rural communities. Each year, Limpopo Province experiences a high number of maternal mortality compared to other provinces. ${ }^{23}$ It is not documented what contributes to this situation. The purpose of this study was to determine the perceived cultural factors contributing to MMR in Ba-Phalaborwa municipality, Mopani District.

\section{Materials and Methods Research Design}

The study was conducted at the Ba-Phalaborwa Local Municipality which is located in Mopani District of Limpopo province, South Africa. There are two surrounding townships in Phalaborwa. A qualitative, exploratory and descriptive research approach was used.

\section{Population and Sampling}

The population sample comprised of women who have passed childbearing age. Non-probability, purposive sampling was used to select participants who met the inclusion criteria. Thirty women, aged 40 years and above childbearing age, who had given birth in their lifetime, were sampled.

\section{Ethical Considerations}

In this study the ethical clearance was obtained from the University of Venda Research Ethics Committee (SHS/16/ PDC/23/1008) and permission to access villages from the Tribal Authorities of villages. All procedures performed which involve the participants were in accordance with the ethical standards of the institutional and research committee and with the 1964 Helsinki Declaration. Informed consent was obtained from all participants. Participants were informed of their right to withdraw from the study without any penalty. Principles of fairness, privacy, confidentiality, anonymity as well as participants' rights to voluntarily participate in the study were adhered to.

\section{Data Collection}

Data was collected using in-depth individual interviews, guided by an un-structured open-ended question "Could you share with me the cultural practices that are practiced for women during the childbirth period in this area?" Open-ended questions gave the participants the opportunity of answering any question in their own words. Probing as communication skills such as reflecting, encouraging and paraphrasing were used to elicit more information and focused on hemorrhage, hypertension and risk of contracting HIV. Data were collected for a period of not more than 45 minutes at the participant's home as per the appointments. Data was collected using Xitsonga and Sepedi as local languages. A voice recorder and field notes were used to capture data.

\section{Data Analysis}

The narrative data from the qualitative un-structured interviews were analyzed using Tesch's open coding method. ${ }^{24}$ The method included the following steps: the researcher read carefully through all the transcripts to get a sense of whole. After the completion of reading all transcripts, a list of similar topics was compiled. Data were grouped per themes and sub-themes and field notes were also coded and categorized. A literature control was done to control the results of the study. ${ }^{25}$

\section{Measures to Ensure Trustworthiness}

Trustworthiness was ensured by applying four principles of Lincoln and Guba's ${ }^{26}$ framework. Credibility was ensured through prolonged engagement, the researchers met with participants during first appointment, data collection and member checks. The experts used dependability to validate the methodology and this was ensured through thick description. Confirmability was ensured by adequate trail audit to determine the conclusions, interpretations and recommendations if traced to their sources.

\section{Presentation of Findings}

The participants were all females aged between 41 and 79 years. Nine participants were married, one widowed and two were single. All participants had borne children in their life time. Eighteen participants were of the XiTsonga ethnic group as this was the main cultural group in the villages selected and twelve were Northern Sotho (Table 1).

Themes and sub-themes that emerged (Table 2) are discussed below. 
Table I Demographic Data for Participants $(\mathrm{N}=30)$

\begin{tabular}{|c|c|c|c|}
\hline & Categories & $\begin{array}{l}\text { No. of } \\
\text { Participants }\end{array}$ & $\%$ \\
\hline Ethnic group & $\begin{array}{l}\text { Northern } \\
\text { Sotho } \\
\text { XiTsonga }\end{array}$ & $\begin{array}{l}12 \\
18\end{array}$ & 60 \\
\hline Age (years) & $\begin{array}{l}40-50 \\
5 I-60 \\
6 I-79\end{array}$ & $\begin{array}{l}10 \\
16 \\
04\end{array}$ & $\begin{array}{l}33 \\
53 \\
14\end{array}$ \\
\hline Marital status & $\begin{array}{l}\text { Married } \\
\text { Single } \\
\text { Widower }\end{array}$ & $\begin{array}{l}20 \\
06 \\
04\end{array}$ & $\begin{array}{l}66 \\
20 \\
14\end{array}$ \\
\hline Parity & $\begin{array}{l}\mathrm{I}-2 \\
3-4 \\
5 \text { nd above }\end{array}$ & $\begin{array}{l}14 \\
06 \\
10\end{array}$ & $\begin{array}{l}47 \\
20 \\
33\end{array}$ \\
\hline Educational level & $\begin{array}{l}\text { High school } \\
\text { Primary school } \\
\text { Tertiary }\end{array}$ & $\begin{array}{l}08 \\
20 \\
02\end{array}$ & $\begin{array}{l}27 \\
67 \\
06\end{array}$ \\
\hline $\begin{array}{l}\text { Beliefs for health- } \\
\text { seeking behavior }\end{array}$ & $\begin{array}{l}\text { Traditional } \\
\text { health practices } \\
\text { Faith based } \\
\text { beliefs } \\
\text { Western }\end{array}$ & $\begin{array}{l}12 \\
08 \\
10\end{array}$ & $\begin{array}{l}40 \\
27\end{array}$ \\
\hline Occupation & $\begin{array}{l}\text { Employed } \\
\text { Unemployed }\end{array}$ & $\begin{array}{l}06 \\
24\end{array}$ & $\begin{array}{l}20 \\
80\end{array}$ \\
\hline
\end{tabular}

\section{Main Theme: Cultural Factors Contributing to Maternal Mortality}

Cultural factors affect the utilization of maternity care services in developing countries. The notion was supported by $\mathrm{Azuh}^{27}$ when reporting that in parts of African countries, women had limited decision-making power in matters of reproduction and sexuality health. The author further corroborated that low status of women and the husbands' domination could contribute to poor utilization of health-care services. Similarly, Hubert ${ }^{28}$ asserted that high levels of maternal mortality were strongly correlated with high levels of social inequality, especially unequal access to health services. The themes and sub-themes that emerged from the main theme (Table 2) will be discussed.

\section{Theme I.I: Perceived Factors Related to Hemorrhage}

Maternal hemorrhage encompasses antepartum, intrapartum, and postpartum bleeding. In an optimal setting, patients who are at high risk of hemorrhage are referred to tertiary care institutions which have multidisciplinary
Table 2 Main Theme, Themes and Sub-Themes That Emerged from the Data Analysis

\begin{tabular}{|c|c|c|}
\hline Main Theme & Themes & Sub-Themes \\
\hline $\begin{array}{l}\text { I. Cultural } \\
\text { factors } \\
\text { contributing to } \\
\text { maternal } \\
\text { mortality }\end{array}$ & $\begin{array}{l}\text { I.I. Perceived cultural } \\
\text { factors related to } \\
\text { hemorrhage } \\
\text { I.2. Perceived cultural } \\
\text { factors related to } \\
\text { hypertension } \\
\text { I.3. Perceived cultural } \\
\text { factors contributing to } \\
\text { risk of contracting } \\
\text { HIVIAIDS }\end{array}$ & $\begin{array}{l}\text { I.I.I. Culture and } \\
\text { knowledge to seek } \\
\text { care } \\
\text { I.I.2. Perceived beliefs } \\
\text { related to hemorrhage } \\
\text { I.2.I. Perceived beliefs } \\
\text { and practices related } \\
\text { to signs of } \\
\text { hypertension } \\
\text { I.2.2. Decision-making } \\
\text { process related to self- } \\
\text { care of hypertension } \\
\text { I.3.I. Cultural } \\
\text { expectations from } \\
\text { childbearing females } \\
\text { I.3.2. Negative } \\
\text { attitudes towards } \\
\text { condom use to } \\
\text { prevent risk of } \\
\text { contracting the virus }\end{array}$ \\
\hline
\end{tabular}

teams who are prepared to care for and deal with known and unknown potential complications. Most participants conveyed that they do not know the actual difference between hemorrhage and normal bleeding which is known as lochia post-delivery.

\section{Sub-Theme I.I.I: Culture and Knowledge to Seek Care}

Socio-cultural factors may primarily influence decision making on whether to seek care, and to reach a care facility in time. ${ }^{29}$ In an African rural setting, knowledge to seek care lies firstly on cultural views. Culture often determines how individuals view diseases, and other related conditions. Some individuals would first seek care at churches and traditional healers since one may believe that it is spiritual work and not ordinary conditions which may need medical attention. Participant number 02 supported this when saying that:

During pregnancy every time I fell sick or feel unwell, I first use church tea which I drink almost every day or herbs, then if the condition does not change I go to church to talk to the elders and the pastor for stronger herbs and prayers. I only visit the clinic if the situation gets worse.

Participant number 03 supported this by saying: "We have a very strong traditional doctor around here. Since I was bleeding during my 2 nd trimester, it was believed that my enemies wanted to take my child away and use him/her 
against me. But days later I bled more. I was taken to hospital, and I lost my baby.“

\section{Sub-Theme I.I.2: Perceived Cultural Beliefs Related to Hemorrhage During Childbirth}

Amongst African rural communities, people perform rituals and undertake consulting with traditional doctors for medications in the belief that they heal better than western medication. These practices are deeply rooted and embedded in these societies, and therefore they become part of the people's lifestyle. It was noted that community members were innate to such an extent that it was difficult to change the beliefs and practices, as they adhered to them throughout their entire lives. Individuals adhered to their grandparent's knowledge in the belief that they know better since they were there before them. Participant number 01 indicated that:

"Few days after giving birth, I had cramps and started bleeding profusely. My grandmother said it was a good sign that all pregnancy particles were coming out of my body. And with cramps she said that it was because that maybe I gave birth on the bed which a woman had miscarriage on previously.

In turn if no medical attention is given, implications on the health status of the individual may be severe. The mother was experiencing post-partum hemorrhage which, if left untreated, might have caused her to bleed to death.

Participant number 11 indicated that: "After my younger sister gave birth, she was bleeding; I thought she wasn"t stitched properly since she had an episiotomy. But then my mother insisted that we take her to a traditional doctor as it was believed that if this condition is treated medically one will always fall sick. So my family took her to a traditional healer so that in future that condition may not happen. She stayed at the traditional healer's house. But after a few hours we were called back and told that she had passed on.

Postpartum hemorrhage can lead to maternal death within hours, and this can be worse if there is a delay in recognizing emergency obstetric complications and making prompt decision to seek care.

\section{Theme 1.2: Perceived Cultural Factors Related to Hypertension}

Hypertensive disorders of pregnancy contribute to severe morbidity, long-term disability and death among both mothers and their babies. However, deaths due to preeclampsia and eclampsia could be avoidable through the provision of timely and effective care to the women presenting with these complications.

Sub-Theme 1.2.I: Perceived Beliefs and Practices Related to Signs of Hypertension

Delay in medical attention has negative effects both on the fetus and the mother. Early detection of hypertension is important for assuring appropriate management and referral of women at risk of developing eclampsia including appropriate treatment. However, the traditional beliefs tended to cause delay in seeking medical attention, as elders were perceived to know much better about medical conditions, hence they would do what their elders did and how their culture was practiced.

Participant 15 indicated that: "In my family we have one or two kind of herbs which can help heal a sick patient. Since I am overweight, during my third pregnancy I developed swollen feet. My grandmother would pour the herbs in a bowl and tell me to soak my feet. But that didn't help; I had to visit the clinic 3 days later.

Fraser et al, ${ }^{16}$ pointed that weight gain during pregnancy comprised the products of conception (fetus, placenta, and amniotic fluid) and hypertrophy of several maternal tissues (uterus, breasts blood, fat stores and extracellular and extravascular fluid). The authors further indicated that optimal weight gain for an average pregnancy is $12.5 \mathrm{~kg}$, of which $9 \mathrm{~kg}$ is gained in the last 20 weeks of pregnancy. The fluid retention can further add up to $25 \%$ of a pregnant woman's weight.

\section{Sub-Theme 1.2.2: Decision-Making Process Related to Self-Care of Hypertension}

Decision making among black African communities lies mostly with the men, as the patriarchal system still dominates even to this day. Women have limited decisionmaking abilities on their reproductive and sexual health. As a sign of respect, women have to be submissive to their husband and this can also contribute to maternal morbidity and mortality.

Participant number 10 indicated that: "I have a lot of jobs to do daily. I clean the yard and the house. Cook for my 5 children and husband, do laundry and other things. I cannot just go to the hospital. If I just leave, who will take care of my husband and children? When I am sick, I try to be strong just for my family. My husband is the one who gives me permission to visit the clinic since it is a bit far. It is only during antenatal period of pregnancy that I 
can go to the clinic at due time, but I go there early so that by noon I'm back."

The results of the study by James et $\mathrm{al}^{19}$ indicated that swelling of the legs was associated with superstition. Complications of hypertension in pregnancy remained the common direct cause of maternal deaths. Fraser et $\mathrm{al}^{16}$ pointed out that normally $9 \mathrm{~kg}$ is gained in the last 20 weeks of pregnancy. When the woman gains weight rapidly before the 20th week of gestation that should be investigated. Furthermore, cultural factors apparently affect the utilization of maternity care services in developing.

\section{Theme I.3: Perceived Cultural Factors Contributing to Risk of Contracting HIVIAIDS}

Polygamy is a common marital practice for many African cultures. $^{30,31}$ Certain prevalent cultural norms and practices related to sexuality contribute to the risk of contracting HIV/AIDS. Some participants indicated that they practice culture so that they may not cause feuds between family members. Some practices which includes polygamy or bearing children for your sibling. This practice could result in power inequality and engaging in unprotected sex, as women have limited ability to negotiate protected sex. Sub-themes that emerged are discussed below.

\section{Sub-Theme 1.3.I: Cultural Expectations from Childbearing Females}

The importance of fertility in African communities may hinder the practice of safer sex. It was understood that if one does not bear children, the in-laws may chase away the woman or even encourage the husband to get himself another wife. This exposes one to unsafe sex practices due to cultural expectations of having children as a sign of femininity. Such practices may lead to polygamy which is now less practiced in the rural area, yet men tend to have more sexual partners. This is a myth with goes that men biologically are programmed to need sex and one woman cannot satisfy them.

Participant number 20 indicated that "As a wife, you should do what is expected of you. Most marriages without children, do not survive. Children are the foundation of the marriage. The man negotiates for sex and you do as he says. Obeying your husband makes the marriage strong"

And while participant number 13 indicated that:

It is culturally acceptable to bear children for your sibling. If your sibling cannot bear children, you have to sleep with her husband to bear children to them. If you disagree the family might take it that you are jealous of their marriage.
For most of the ethnic groups, the husband has been assumed to be head of the household. The husband had dominance in decision making in the family including when he will have sex with his wife or wives.

\section{Sub-Theme 1.3.2: Negative Attitude Towards Condom Use to Prevent Risk of Contracting the Virus}

Negative attitude towards use of condoms influences individuals on refraining from using condoms. It was emerged that "Flesh to flesh" sexual activity gives more pleasure than using condoms.

Participant number 19 indicated that: "Lack of trust is associated with use of condom. Initiating to use a condom means that you do not trust your partner and I feel like there is no need for me to use a condom because I trust my husband and he trusts me too".

While participant number 16 stated that: "My man complains that condoms interfere with sexual pleasure, they deter sexual activity by reducing sensitivity and sometimes causing dry sex. He always tells me a quote in which he says "how can you eat a sweet in a plastic?" A condom in which he refers as a plastic....

Participant number 08 indicated that:

It is embarrassing to purchase condoms. The cashier looks at you in a nasty way. Even at the clinics, when I take my child for immunization, I only take the condoms when nobody is looking.

\section{Discussion}

The findings of the study revealed the perceived cultural factors contributing to maternal mortality associated with hemorrhage, hypertension and contracting of HIV in BaPhalaborwa municipality. How the community members adhered to their culture, determined how they viewed diseases, and other relative conditions. When they were sick, they displayed knowledge deficit, and consulted their indigenous healers. Abdul et $\mathrm{al}^{32}$ stated that culture and ethnicity created a unique pattern of beliefs and perceptions as to what "health" or "illness" mean. These beliefs influenced how symptoms are recognized, to what they are attributed, and how they are interpreted and affects, how and when health services are sought. ${ }^{33}$ The socio-cultural attitudes influence the state of health, affects their entire affairs, diseases and health inclusive. ${ }^{34}$ According to Onyeabochukwu, ${ }^{35}$ cultural beliefs not only shape how individuals respond to forms of disease and illness but 
also choices about which forms of care should be accessed. The findings also revealed that women or their families may have been unaware of the need for care or of the warning signs of problems in pregnancy or sociocultural barriers prevented this. ${ }^{36}$

When women had heavy bleeding, this was perceived as providing a "healthy clean-out of the womb," and this contributed to delay in presentation for professional care. This was supported by a study done by Sychareun ${ }^{37}$ when indicating that reliance on traditional medicines may present a barrier to postpartum care. Traditional medicine approaches may be deeply valued among the females who are deeply rooted within culture. Similarly, this was a trend among black rural communities in Limpopo because they were still rooted in the spiritual and cultural belief system. ${ }^{37}$

Women were also lacking accurate information on development of hypertensive disorders. They did not know at which stage of pregnancy they should gain weight. Excessive weight gain was considered normal. The Department of Health, ${ }^{38}$ and Sellers ${ }^{39}$ pointed out that signs and symptoms of PIH include edema, severe headache, blurry vision and excessive nausea and vomiting. These signs develop slowly whereas in some women they develop in a sudden way without warning. Fraser et $\mathrm{al}^{16}$ pointed that oedema due to PIH puts on pressure and may be found in non-dependent anatomical areas such as the face, hands, lower abdomen, vulva and sacral areas. Cultural groups may choose to retain traditional health practices for a variety of reasons, including belief in the efficacy of traditional healing practices or due to difficulties of accessing western health care services. ${ }^{40}$ Abdul et $\mathrm{al}^{32}$ mentioned that this pattern of beliefs influences how symptoms are recognized, to what they are attributed, and how they are interpreted and affects the health services. This further influences the decision-making process related to self-care when suffering from hypertension. Azuh ${ }^{27}$ reported that women's decision-making power was limited, particularly in matters of reproduction and sexuality. He further ascertained that issues such as low status of women and husband's domination all worsen the poor outcomes and poor utilization of health-care services.

Findings further revealed cultural factors contributing to the risk of contracting HIV/AIDS. Women could not insist on condom use as their husbands decide. The powerlessness of the woman to negotiate conditions favoring her was even made worse when she was illiterate, poor, and a rural dweller. $^{41}$ Women further displayed negative attitude towards condom use to prevent risk of contracting the virus. This notion was supported by Masoda and
Govender ${ }^{42}$ who found that there was resistance to the use of condoms because of religious and cultural beliefs, education levels, myths, and personal perceptions. Whereas consistent condom use had negative associations with being married or in a cohabiting relationship, it is documented and it is believed that condoms were safe and those who had multiple partners were more likely to be consistent users.

\section{Limitations}

Only 30 child-bearing women of Mopani district of Limpopo province were involved in the study. Findings will not be generalized to other districts of Limpopo Province.

\section{Recommendations}

1. Women, especially from their teenage years, must be educated about pregnancy, danger signs of pregnancy, possible complications and what they mean so that they can seek medical assistance early.

2. Facilitate capacity building for the families to minimize male dominance on when females should seek medical assistance.

3. Build capacity on awareness and perceptions among the community members of the causes of maternal deaths which will influence their decision to seek help in the face of an emergency.

4. Provision of information and subsequently education on HIV/AIDS and pregnancy.

5. Provide information on self-care during pregnancy, intrapartum and postpartum, including male involvement in reproductive health care.

6. Integrating cultural beliefs, myths and practices in care provision to minimize its detrimental effects on women's reproductive health

\section{Conclusion}

Most women believed and practiced cultural rituals which were passed on from generations to generations. It was noted with concern that women were not aware that these cultural factors under hypertension, hemorrhage and HIV/AIDS can contribute to maternal morbidity and mortality. It was evident that culture was fully adhered to. Knowledge deficit on danger signs and ignorance about when to seek care health care may also contribute to maternal mortality as complications of pregnancy may continue. Misconceptions about the use of condoms amongst sexually active individuals tend to lead to unprotected sex and exposed them to contract the 
virus. Cultural practices such as bearing children for siblings seemed normal, although this was viewed as very dangerous activity. Siblings sleep with their own partners and in turn, sleep with their sibling's partners which results in unprotected sex in order to bear them children. This activity can spread HIV/AIDS very fast.

\section{Data Sharing Statement}

The raw data used to support the findings of this study are included within the article and can be available from the corresponding author upon request.

\section{Compliance with Ethical Standards}

Ethical clearance was obtained from the University of Venda Research Ethics Committee; it was conducted following the Declaration of Helsinki. Written, informed consent was obtained from participants. Participants were informed of their right to withdraw from the study without any penalty. Principles of fairness, privacy, confidentiality, anonymity as well as participants' rights to voluntarily participate in the study were considered.

\section{Acknowledgments}

The researchers would like to acknowledge the University of Venda and Ba-Phalaborwa Municipality officials who permitted the team to conduct this study. All women who participated in this study and the South African Medical Research Council are acknowledged.

\section{Author Contributions}

The project was funded by South African Medical Research Council (SAMRC), the project leader was L.M. N, M.P.M was an Honours student recruited in the project and M.S.M was a supervisor with D.U.R a co-supervisor. The student under supervision was involved in conceptualization, data collection, analysis and report writing, drafting of and article writing. L.M.N, M.S.M and D.U.R conducted literature search. All authors contributed to data analysis, drafting and revising the article, gave final approval of the version to be published, and agree to be accountable for all aspects of the work.

\section{Funding}

The South African Medical Research Council and the University of Venda Research and Publication Committee for financial assistance.

\section{Disclosure}

The authors report no conflicts of interest in this work.

\section{References}

1. Statistics South Africa. Millennium Development Goals. Goal 5: improve Maternal Health; 2010. Available from http://www.statssa. gov.za/MDG/2010_.pdf. Accessed 20 April 2017.

2. Department of Health. Saving Mothers 2017: Annual Report on Confidential Inquiries into Maternal Death in South Africa. Pretoria: Government Print; 2018.

3. Department of Health. Saving Mothers 2011-2013: Sixth Report on the Confidential Enquiries into Maternal Deaths in South Africa. Pretoria: Government Print; 2013.

4. World Health Organisation (2014). Maternal mortality Fact sheets. Available from http://www.who.int/reproductivehealth/en/. Accessed 30 March 2017.

5. Department of Health. Saving Mothers 2008-2010: Fifth Report on the Confidential Enquiries into Maternal Deaths in South Africa. Pretoria: Government Print; 2011.

6. Zureick-Brown C, Wilmoth JR, Mizoguchi N, et al. State Politics and Policy Journal. N Method Deriv Global Estimates Mater Mortality. 2012;3(2):2151-7509.1038.

7. Igberase GO, Isah EC, Igbekoyi OF. Awareness and perception of maternal mortality among women in a semi-urban community in the Niger Delta of Nigeria. Ann Afr Med. 2009;8(4):261-265. doi: $10.4103 / 1596-3519.59582$

8. Okolocha C, Chiwuzie J, Braimoh S, Unuigbe J, Olumeko P. Sociocultural factors in maternal mortality: A study of a semi-urban community in Southern Nigeria. J Epidemiol Community Health. 1998;52:293-297. doi:10.1136/jech.52.5.293

9. Mills S, Bertrand JT. Use of health professionals for obstetric care in northern Ghana. Stud Fam Plann. 2005;36(1):45-56. doi:10.1111/ j.1728-4465.2005.00040.x

10. Bazzano AN, Kirkwood B, Tawiah-Agyemang C, Owusu-Agyei S, Adongo P. Social costs of skilled attendance at birth in rural Ghana. Int $J$ Gynecol Obstetrics. 2008;102(1):91-94. doi:10.1016/j. ijgo.2008.02.004

11. Addai I. Determinants of use of maternal-child health services in rural Ghana. $J$ Biosoc Sci. 2000;32(1):1-15. doi:10.1017/ S0021932000000018

12. Cole M, Packer M. Culture in prenatal development: parental attitudes, availability of care, expectations, values, and nutrition. Child Youth Care Forum. 2011;43(4):521-538.

13. Geller SE, Goudar SS, Adams MG, et al. Factors associated with acute postpartum hemorrhage in low risk women delivering in rural India. Int $J$ Gynaecol Obstetrics. 2008;101(1):94-99. doi:10.1016/j.ijgo

14. Shaikh BT, Hatcher J. Health seeking behaviour and health service utilization in Pakistan: challenging the policy makers. $J$ Public Health (Bangkok). 2005;27(1):49-54. doi:10.1093/ pubmed/fdh207

15. Department of Health. Saving Mothers 2008-2010: Fifth Report on the Confidential Enquiries into Maternal Deaths in South Africa. Pretoria: Government Print; 2010.

16. Fraser D, Cooper MA, Nolte AWG. Myles Textbook for Midwives, Fourteenth Edition. Elsevier; 2009.

17. Solomon CG, Seely EW. Hypertension in pregnancy. Endocrinol Metab Clin North Am. 2006;35(1):157-171. doi:10.1016/j. ecl.2005.09.003

18. Bellamy L, Casas JP, Hingorani AD, Williams DJ. Pre-eclampsia and risk of cardiovascular disease and cancer in later life: systematic review and meta-analysis. $B r$ Med J. 2007;335(7627):974. doi:10.1136/bmj.39335.385301.BE 
19. James OE, Mgbekem MA, Edem OA. Knowledge, Attitude and preventive practices towards pregnancy induced hypertension among pregnant women in General Hospital Calabar, Cross River State, Nigeria. Pak J Social Sci. 2009;6:1-5.

20. Ouyang DW, Economy KE, Norwitz ER. Obstetric complications of fibroids. Obstet Gynecol Clin North Am. 2006;33(1):153-169. doi:10.1016/j.ogc.2005.12.010

21. Maputle MS, Khoza LB, Lebese RT. Knowledge towards pregnancyinduced hypertension among pregnant women in Vhembe District, Limpopo Province. J Human Ecolo. 2015;51(1,2):47-54. doi:10.1080/09709274.2015.11906893

22. Malcolm GM, Oskari H, Rohana H, Jaydeep DTI, Fraser I. The need for investigations to elucidate causes and effects of abnormal uterine bleeding. Semin Reprod Med. 2011;29(5):410-422. doi:10.1055/s0031-1287665

23. Statistics South Africa. (2012). Mortality and causes of death in South Africa. 2012: findings from death notification Statistics South Africa. Available from www.statssa.gov.za. Accessed 18 March 2017.

24. de Vos AS, Strydom H, Fouche CB, Delport CLS. Research at Grass Roots for the Social Sciences and Human Service Professions. 4th ed. Pretoria: van Schaik Publishers; 2011.

25. Creswell JW. Research Design: Qualitative, Quantitative and Mixed Methods Approach. London: Sage Publications Incorporated; 2009.

26. Lincoln YS, Guba EG. Naturalistic Inquiry. Beverly Hills, CA: Sage Publications; 1985.

27. Azuh DE, Azuh AE, Iweala EJ, Adeloye D, Akanbi M, Mordi RC. Factors influencing maternal mortality among rural communities in South western Nigeria. Int $J$ Womens Health. 2017;9:179-188. doi:10.2147/IJWH.S120184

28. Hubert C. Maternal Mortality Trends in Mexico: State Differences. Population Research Center, Chubert@Prc.Utexas.Edu. Texas, University of Texas at Austin; 2013.

29. Gabrysch S, Campbell OM. Still too far to walk: literature review of the determinants of delivery service use. BMC Pregnancy Childbirth. 2009;9(1):34. doi:10.1186/1471-2393-9-34

30. Abass K, Sakoalia P, Mensah C. Socio-cultural practices and male involvement in reducing maternal mortality in rural Ghana. The case of Savelugu/Nanton District of the Northern Region of Ghana. Int $J$ Asian Social Sci. 2012;2(11):2009-2026.
31. Al-Krenawi A, Graham J, Izzeldin A. The psychosocial impact of polygamous marriages on Palestinian women. Women Health. 2001;34(1):1-16. doi:10.1300/J013v34n01_01

32. Abdul MM, Onose M, Ibrahim MT, et al. An Analysis of SocioEconomic, Sociocultural, Religious, Environmental, Technological, Language and Educational Factors on Women's Right in Nigeria. Sponsored by Spanish Agency for International Development Cooperation and Fundación Mujeres; 2012.

33. Ajiboye OE, Adebayo KA. Socio-cultural factors affecting pregnancy outcome among the Ogu speaking people of Badagry area of Lagos state. Nigeria. 2012;2(4):133-136.

34. Uzobo E, Ogbanga MM, Jackson J. Socio-cultural factors and attitudes affecting the health status of rural communities: a study of Danmusa, Katsina State, Nigeria. Int J Sci Res. 2014;3(3):837-844.

35. Onyeabochukwu DA. Cultural Practices and Health: The Nigerian Experience. Enugu: University of Nigeria; 2007.

36. Narasimhan M, Loutfy M, Khosla R, Bras M. Sexual and reproductive health and human rights of women living with HIV. J Int AIDS Soc. 2015;18(6:5):20834.

37. Sychareun V, Phengsavanh A, Hansana V. Cultural Beliefs and Traditional Rituals About Child Birth Practices in LAO PDR. Kuala Lumpur: The Asian-Pacific Resource \& Research Centre for Women (ARROW); 2009.

38. The Department of Health. Saving Mothers 2005-2007: Fourth Report on Confidential Enquiries into Maternal Deaths in South Africa. Pretoria: Government Printers; 2007.

39. Sellers PM. Midwifery: A Textbook and Reference Book for Midwives in South Africa. Cape Town: Juta \& Company. Ltd; 2002.

40. Tremayne S. Managing Reproductive Life: Cross-Cultural Themes in Fertility and Sexuality. New York: Berghahn Books; 2010.

41. Onyema MC. Socio-Cultural Factors Influencing Maternal Mortality in Ngbo Clan, Ohaukwu Local Government Area of Ebonyi State. Thesis submitted at University of Nigeria for fulfillment of M.Sc. Degree in Sociology and Anthropology (Medical Sociology); 2011.

42. Masoda M, Govender I. Knowledge and attitudes about and practices of condom use for reducing HIV infection among Goma University students in the Democratic Republic of Congo. South Afr J Epidemiol Infect. 2013;28(1):61-68. doi:10.1080/10158782.2013.11441521
International Journal of Women's Health

\section{Publish your work in this journal}

The International Journal of Women's Health is an international, peerreviewed open-access journal publishing original research, reports, editorials, reviews and commentaries on all aspects of women's healthcare including gynecology, obstetrics, and breast cancer. The manuscript management system is completely online and includes a very quick and fair peer-review system, which is all easy to use. Visit http://www.dovepress.com/testimonials.php to read real quotes from published authors. 